\title{
PEKERJAAN PONDASI TIANG PANCANG: CARA PEMANCANGAN, KENDALA DAN TEKNOLOGI TERBARU
}

\author{
Nina Nurdiani \\ Architecture Department, Faculty of Engineering, Binus University \\ Jl. K.H. Syahdan No. 9, Palmerah, Jakarta Barat 11480 \\ nnurdiani@binus.edu; nina.nurdiani@yahoo.co.id
}

\begin{abstract}
The foundation work a building project is commonly done when students conducted Real Estate Internship which leads to inadequate knowledge of foundation work obtained during internship, especially the pile foundation work. Related to this condition it is necessary to study the technical specifications of a pile foundation commonly used on a project, how to pile, problems encountered at the field, and the latest technology to reduce obstacles at the field. The study is conducted with a descriptive approach towards building projects in Jakarta built in 2008, when the latest technology of pile foundation came to Indonesia. The results of the study provide knowledge that the pile foundation is made of hard wood, concrete and steel. The form of pile foundations is generally triangular or rectangular. Many building projects use concrete pile foundation with steel reinforcement and spiral reinforcement. The advantages of using concrete pile foundation are in order to be efficient, convenient and practical. Piling foundation uses a drop hammer or jacked piling system to the hard ground. Obstacles encountered in the field are the soft soil conditions, the former marsh or land fill. Hydraulic Static Pile Driver (HSPD) or 'Press in Pile' is the latest method as a solution to pile the piling foundation in dense residential neighborhood. This technique can reduce or even eliminate the effects that interfere with the environment (vibration, air pollution and noise pollution) when piling the pile foundation. In general, the technology 'Press in Pile' reduces environmental problems as well as provides more convenient, faster and economical effects.
\end{abstract}

Keywords: how to pile, pile foundation, problems, the latest technology

\begin{abstract}
ABSTRAK
Pekerjaan lapangan pada proyek pembangunan gedung yang ditemui mahasiswa saat melakukan kegiatan Kerja Praktek Real Estat umumnya sudah melewati tahap pekerjaan pondasi. Kondisi demikian menyebabkan pengetahuan terkait pekerjaan pondasi masih terbatas, khususnya pekerjaan pondasi tiang pancang (pile). Terkait dengan hal tersebut, perlu studi untuk mengetahui spesifikasi teknis pondasi tiang pancang (pile) yang umum digunakan pada proyek, cara pemancangan pondasi tiang pancang (pile), kendala yang ditemui di lapangan, serta teknologi terbaru yang dapat mengurangi kendala di lapangan. Studi dilakukan dengan pendekatan deskriptif pada proyek-proyek pembangunan gedung di Jakarta yang dibangun pada tahun 2008, saat teknologi terbaru pemancangan tiang pancang masuk ke Indonesia. Hasil studi memberikan pengetahuan bahwa pondasi tiang pancang dapat terbuat dari kayu keras, beton dan baja. Penampang pondasi dapat berbentuk segitiga atau segiempat. Saat ini proyek-proyek pembangunan gedung lebih banyak menggunakan pondasi tiang pancang beton dengan baja tulangan serta tulangan spiral. Keuntungan menggunakan tiang pancang beton adalah pengerjaan pondasi menjadi efisien, mudah dan praktis. Cara pemancangan tiang pancang banyak yang menggunakan drop hammer atau sistem jacked piling sampai menyentuh tanah keras. Kendala yang ditemui di lapangan adalah kondisi tanah yang lembek, bekas rawa atau tanah urukan yang dapat mengganggu pemancangan pondasi. Teknologi Hydraulic Static Pile Driver (HSPD) atau 'Press in Pile' adalah metode pemancangan terbaru sebagai solusi pemancangan pondasi tiang pancang pada lingkungan padat hunian. Teknik ini mengurangi bahkan dapat menghilangkan dampak yang mengganggu lingkungan (getaran, polusi udara dan polusi suara) saat pemancangan tiang pancang. Secara umum teknologi 'Press in Pile' mengurangi masalah lingkungan, lebih praktis, lebih cepat dan lebih ekonomis.
\end{abstract}

Kata kunci: cara pemancangan, kendala, pondasi tiang pancang, teknologi terbaru. 


\section{PENDAHULUAN}

Kegiatan kerja praktek real estat (real estate intership) yang dilakukan oleh mahasiswa untuk memenuhi persyaratan pemenuhan kurikulum di Jurusan Arsitektur, sejauh ini masih didominasi oleh kegiatan kerja praktek pada proyek-proyek di lapangan. Proyek di lapangan tersebut ada yang berupa proyek rumah tinggal, rumah-toko (ruko), kantor dan apartemen. Kegiatan proyek pembangunan gedung dimulai dari pekerjaan pondasi sampai dengan pekerjaan finishing. Umumnya pekerjaan lapangan pada proyek pembangunan gedung yang ditemui mahasiswa sudah melewati tahap pekerjaan pondasi. Kalaupun ada pekerjaan pondasi yang masih bisa diikuti mahasiswa, biasanya berupa pekerjaan pondasi lajur dari batu kali dan pondasi setempat dari beton bertulang. Kondisi demikian menyebabkan pengetahuan terkait pekerjaan pondasi masih terbatas, khususnya pekerjaan pondasi tiang pancang (pile). Padahal jenis pondasi ini adalah yang banyak digunakan pada proyek-proyek pembangunan gedung bertingkat di Jakarta pada saat ini.

Dari penjelasan di atas, perlu studi mendalam terkait pengetahuan mengenai pondasi tiang pancang untuk proyek bangunan, pelaksanaan pekerjaan pondasi tiang pancang di lapangan, dan kendala yang terjadi di lapangan terkait pekerjaan pondasi serta teknologi terbaru terkait pekerjaan pondasi tiang pancang.

Melihat terbatasnya peluang mahasiswa dalam mendapatkan pengetahuan terkait pelaksanaan pekerjaan pondasi tiang pancang (pile) pada proyek-proyek pembangunan gedung, studi ini fokus pada mempelajari permasalahan mengenai: (1) bagaimana spesifikasi teknis pondasi tiang pancang (pile) yang umum digunakan pada proyek?; (2) bagaimana cara pemancangan pondasi tiang pancang (pile) dilakukan di lapangan?; (3) apa saja kendala yang ditemui di lapangan terkait pekerjaan pondasi tiang pancang (pile)?; (4) teknologi terbaru apa yang dapat mengurangi kendala yang terjadi di lapangan terkait pekerjaan pondasi tiang pancang (pile)?

Tujuan studi ini adalah untuk mengetahui spesifikasi teknis pondasi tiang pancang (pile) yang umum digunakan pada proyek saat ini, cara pemancangan pondasi tiang pancang (pile) di lapangan, kendala yang ditemui terkait pekerjaan pondasi tiang pancang (pile), teknologi terbaru yang dapat mengurangi kendala di lapangan terkait pekerjaan pondasi tiang pancang (pile). Studi ini dilakukan untuk mendukung pengetahuan yang perlu diketahui mahasiswa agar bisa mengetahui perbedaan antara teori dan praktek professional, khususnya pada pekerjaan pondasi tiang pancang (pile).

\section{METODE}

Untuk dapat menjawab permasalahan terkait pekerjaan pondasi tiang pancang pada proyekproyek pembangunan gedung, maka dilakukan studi dengan pendekatan deskriptif pada proyek-proyek pembangunan gedung di Jakarta yang sedang melalui tahap pekerjaan pondasi tiang pancang (pile).

Pengumpulan data dan informasi terkait pekerjaan pondasi dilakukan melalui pengamatan lapangan dan studi data sekunder. Unit analisisnya yaitu pekerjaan pondasi tiang pancang pada proyek yang sudah berjalan di Jakarta, khususnya pada tahun 2008 saat teknologi terbaru pemancangan tiang pancang masuk ke Indonesia (Tekno Konstruksi, 2008). Analisis data dilakukan dengan mengeksplorasi pekerjaan pondasi tiang pancang (pile) di lapangan dari hasil pengamatan lapangan dan data sekunder untuk mempelajari spesifikasi teknis pondasi tiang pancang (pile) yang umum digunakan pada proyek, cara pemancangan pondasi tiang pancang (pile), kendala yang ditemui di lapangan terkait pekerjaan pondasi tiang pancang (pile) dan teknologi terbaru yang dapat mengurangi kendala yang terjadi di lapangan. 


\section{HASIL DAN PEMBAHASAN}

\section{Pondasi Tiang Pancang}

Pondasi tiang pancang adalah salah satu elemen bangunan yang berfungsi memindahkan beban struktur dan beban bangunan ke tanah. Umumnya tiang pancang digunakan atau dipilih apabila kondisi tanah relatif stabil dan kedalaman tanah keras masih terjangkau atau tidak terletak jauh di bawah permukaan tanah. Jenis pondasi tiang pancang tidak dapat digunakan pada kondisi tanah yang berisi batu-batuan. Pondasi tiang pancang dapat terbuat dari kayu keras, beton dan baja (pipa atau profil).

Pondasi tiang pancang kayu terbuat dari pohon kayu keras yaitu kayu ulin atau kayu besi dari Kalimantan, kayu hitam dari Sulawesi, dan kayu Merbau dari Sumatera. Namun karena alasan pelestarian lingkungan, diameter kayu yang terbatas (rata-rata $20 \mathrm{~cm}$ ) dan panjangnya kayu yang terbatas (12 meter sampai 15 meter), juga daya dukung pondasi tiang kayu menjadi sangat terbatas, maka saat ini pondasi tiang kayu sudah jarang digunakan. Kecuali di daerah-daerah pinggir kota jenis pondasi kayu ini masih digunakan. Supaya tiang pancang kayu awet, maka sebelum dipancang tiang/batang kayu ini harus diulas 'ter' terlebih dahulu dan pemasangan tiang kayu ini juga harus berada di bawah air tanah.

Pondasi tiang pancang dari baja lebih cepat pemasangannya dan waktu pelaksanaannya di lapangan. Namun pondasi tiang pancang baja memiliki kendala apabila dipancang di daerah yang lembab tanahnya atau dekat area pantai, karena pondasi tiang dari baja dapat mudah terkena karat.

Pondasi tiang pancang beton memiliki kelebihan dibandingkan dengan pondasi tiang pancang kayu dan pondasi tiang pancang baja yaitu lebih awet, tahan terhadap kelembaban, kekuatan beton mudah disesuaikan dengan kebutuhan, dan pengadaannya melalui prefabrikasi.

Karena kelemahan dan keterbatasan jenis pondasi tiang pancang kayu dan tiang pancang baja, maka saat ini masyarakat lebih banyak menggunakan pondasi tiang pancang beton untuk pembangunan rumah tinggal atau proyek-proyek pembangunan gedung lainnya. Kajian pondasi tiang pancang kali ini juga lebih fokus pada jenis pondasi tiang pancang dari beton.

\section{Pondasi Tiang Pancang Beton}

Material pembentuk tiang pancang beton yang banyak digunakan masyarakat saat ini adalah berupa baja tulangan dan tulangan spiral dengan ukuran tertentu sesuai kebutuhan, serta beton dengan mutu tertentu sesuai kebutuhan. Ukuran penampang tiang pancang dan panjang tiang pancang juga disesuaikan dengan kebutuhan pasar terkait dengan jenis bangunan yang akan dibangun di tapak. Jenis penampang tiang pancang dapat berbentuk segitiga, segiempat dan lingkaran (Gambar 1). Tiang pancang boleh dipancang setelah berumur $>28$ hari dari waktu pembuatannya.

Hal yang perlu diperhatikan dalam pelaksanaan pemancangan pondasi tiang pancang adalah pemancangan setiap (satu) tiang harus dilaksanakan sekaligus dan tidak boleh ditunda atau diteruskan keesokan hari, karena akan menyebabkan pergeseran tiang; tiang harus dipancang dengan cermat dan tepat pada titik-titik sesuai pada gambar kerja; pemancangan tiang harus sampai lapisan tanah keras sesuai data-data dari hasil penyelidikan tanah yang sudah dilakukan sebelum pekerjaan pondasi dimulai; tiang harus dipancang betul-betul tegak lurus dan tepat, karena kemiringan akan menyebabkan bahaya konstruksi pada bangunan. 


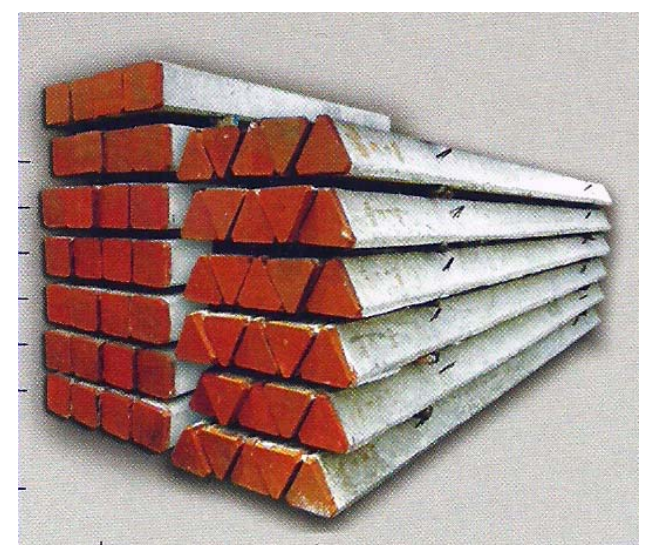

Gambar 1 Tiang pancang beton dengan penampang segitiga dan segi empat (Beton Elemindo Perkasa, 2008)

Untuk memperkokoh bangunan berdiri di atas tanah, tiang pancang akan dipancang menggunakan pengentak diesel yang dahulu menimbulkan polusi udara dan polusi suara. Namun saat ini pemancangan tiang pancang banyak menggunakan drop hammer atau sistem jacked piling sampai menyentuh tanah keras.

Biasanya sebelum dilakukan pemancangan akan diadakan penyelidikan tanah untuk menentukan kedalaman tanah keras. Penyelidikan tanah dilakukan dengan alat bor tanah. Apabila penyelidikan tanah tidak dilaksanakan dengan teliti, akan timbul bahaya. Jika tiang pancang tidak sampai permukaan lapisan tanah keras, kekokohan landasan akan berkurang, dan gedung yang dibangun dapat mengalami penurunan pondasi yang tidak merata atau tidak seragam.

Keuntungan menggunakan tiang pancang: (1) pengerjaan pondasi menjadi jauh lebih cepat dan efisiensi waktu, karena pondasi dibuat di pabrik dengan pengawasan kualitas produk yang prima; (2) pekerjaan pemancangan pondasi mudah dan praktis.

Untuk bangunan rumah tinggal, bangunan industri dan bangunan bertingkat rendah biasanya menggunakan pondasi tiang pancang (mini pile) dengan penampang segitiga atau segiempat, yang memiliki spesifikasi teknik sebagai berikut:

$\begin{array}{ll}\text { Panjang Pile } & : 6 \mathrm{~m} \text { dan } 3 \mathrm{~m} \\ \text { Mutu Beton } & : \mathrm{K}-450 \\ \text { Bentuk Penampang } & \text { : Segitiga atau segiempat } \\ \text { Tulangan Spiral } & : 5 \mathrm{~mm} \text { (toleransi 0,2 mm) } \\ \text { Sambungan Standar } & \text { : Plat sambungan baja di las } \\ \text { Sistem pemancangan } & \text { :Drop Hammer, Jacked in pile }\end{array}$

Penggunaan pondasi tiang pancang beton juga harus memperhatikan kondisi tanah atau kondisi lapangan. Kelemahan yang dapat terjadi pada pondasi tiang pancang beton yang terbuat dari komposisi beton dan baja tulangan adalah adanya korosi baja tulangan. Korosi baja tulangan adalah reaksi kimia atau elektro kimia antara baja tulangan dengan lingkungannya. Proses korosi baja tulangan di dalam beton berlangsung secara karbonasi, degradasi oleh sulfat dan klorida dan leaching (Fahirah, 2007). Fahirah juga menjelaskan dalam penelitiannya bahwa baja tulangan yang terkena korosi mengakibatkan kerusakan beton dan dapat memperpendek usia konstruksi. Untuk dapat mencegah terjadinya korosi maka saat awal mutu baja harus baik dan selimut beton dipertebal. Selain itu harus ada penambahan dimensi struktur, pemampatan beton dan coating.

Selain memperhatikan kelemahan pondasi tiang pancang beton, perlu juga diperhatikan beban yang nanti akan dipikul oleh pondasi tiang pancang. Setiap pondasi harus mampu mendukung beban 
sampai batas keselamatan yang ditentukan, termasuk beban maksimum yang mungkin terjadi. Hasil penelitian menunjukkan bahwa panjang tiang dan jumlah tumpukan tiang pancang mempengaruhi daya dukung tiang pancang (Nugroho, et.al, 2011).

\section{Cara Pemancangan Tiang Pancang}

Ada dua cara atau sistem pemancangan tiang pancang. Pertama adalah drop hammer system (Gambar 2). Dengan spesifikasi teknik sbb: tipe tiang yang digunakan adalah segitiga $(28 \mathrm{~cm} ; 32 \mathrm{~cm}$ ) atau segiempat $(20 \mathrm{~cm} ; 25 \mathrm{~cm})$, inggi jatuh hammer adalah 1 meter, berat hammer adalah $1500 \mathrm{~kg}$. Keuntungannya adalah harga Mob / Demob murah seta mobilisasi dan setting alat pancang cepat.

Cara kedua adalah hydraulic jacked piling system (Gambar 3), dengan spesifikasi teknik: tipe tiang yang digunakan adalah segiempat $(20 \mathrm{~cm} ; 25 \mathrm{~cm})$, kapasitas tekan segiempat $20 \mathrm{~cm}$ adalah 70 ton, kapasitas tekan segiempat $25 \mathrm{~cm}$ adalah 100 ton, dan sistem tekan jaw system. Keuntungan cara ini adalahh detaran saat pemancangan sangat sedikit, bahkan tidak ada sama sekali, serta tidak ada suara bising akibat pukulan hammer karena menggunakan sistem hydrolik..

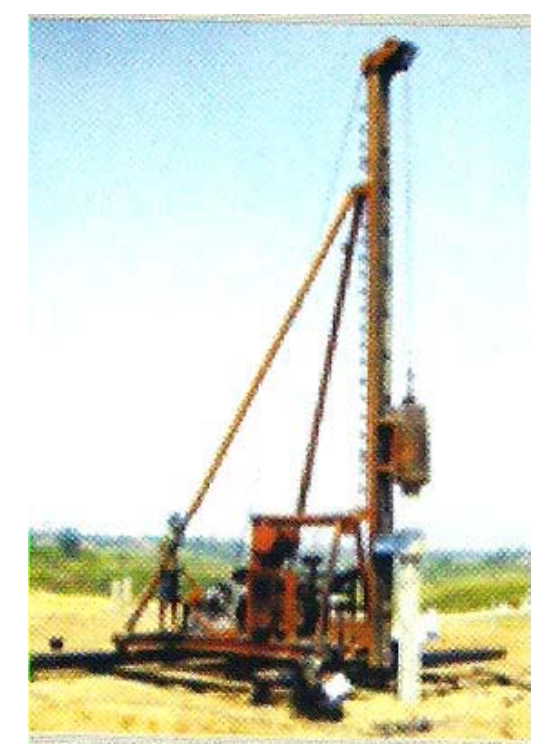

Gambar 2 Drop Hammer System (Beton Elemindo Perkasa ,2008)

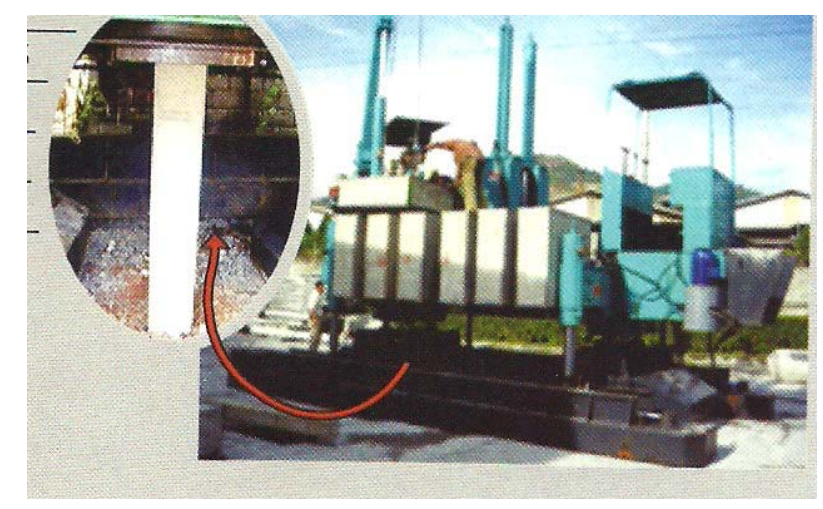

Gambar 3 Hydraulic Jacked Piling (Beton Elemindo Perkasa ,2008) 
Pemancangan tiang pancang bisa memilih salah satu diantara dua cara pemancangan yang sudah dijelaskan di atas, yang disesuaikan dengan kebutuhan dan kondisi eksisting lingkungan sekitar tapak yang akan dibangun. Area pemancangan diupayakan memiliki ruang bebas untuk memudahkan pemancangan tiang pancang. Setelah dipancang, tahapan pekerjaan selanjutnya adalah: (1) tiang pancang disambung dengan cara dilas di antara kedua pelat besi; (2) final set dilakukan untuk memastikan dan menjamin tiang pancang sudah mencapai tanah keras, serta mengecek kembali hasil pemancanganuntuk memenuhi standar ketepatan pemancangan.

\section{Kendala di Lapangan terkait Pekerjaan Pondasi Tiang pancang}

Pelaksanaan pekerjaan pondasi tiang pancang di lapangan tidak selalu berjalan lancar. Kadang ada hal yang menghambat pekerjaan yang ditemui oleh kontraktor saat memancang tiang pancang. Di bawah ini adalah berbagai kendala yang umum terjadi terkait pemancangan tiang pancang:

Pertama adalah kondisi tanah yang tidak begitu baik, misalnya tanah di lapangan kondisinya lembek, akan mengganggu pemancangan pondasi. Kondisi tanah yang lembek di lokasi menyebabkan dorongan tanah ke samping cukup besar. Tiang pancang yang telah dipersiapkan bisa saja menjadi miring, sehingga perlu pemancangan baru atau pemancangan ulang. Untuk menstabilkan kondisi tanah yang lembek maka diperlukan dewatering yang cukup. Pekerjaan tanah juga dilakukan dengan cara open cap, yaitu galian tanah dibuat terasering yang cukup lebar sehingga bebannya tidak terlalu kuat. Saat penggalian tanah, disarankan untuk tidak menimbun tanah galian terlalu banyak, karena dikhawatirkan akan membebani tanah itu sendiri. Sehingga timbunan tanah galian harus segera dikeluarkan dalam satu hari.

Kendala lainnya adalah kondisi tanah bekas rawa dan urukan. Kondisi tanah seperti ini menimbulkan pergerakan horisontal ketika dilakukan pemancangan tiang pancang. Pada saat kondisi curah hujan dan muka air tanah cukup tinggi, tanah bekas rawa dan urukan juga dapat menimbulkan longsor pada saat pekerjaan galian tanah untuk basement. Hal ini dapat diatasi dengan dewatering yang cukup.

\section{Teknologi 'Press in Pile', Metode Terbaru Pemancangan Tiang Pancang}

Teknologi Hydraulic Static Pile Driver (HSPD) atau dikenal dengan nama 'Press in Pile' merupakan metode pemancangan terbaru sebagai solusi pemancangan pondasi tiang pancang pada lingkungan padat hunian. Secara umum teknologi 'Press in Pile'mengurangi masalah lingkungan saat pekerjaan pemancangan pondasi tiang pancang, lebih praktis, lebih cepat dan lebih ekonomis.

Kelebihan teknologi Hydraulic Static Pile Driver (HSPD): (1) tidak menimbulkan getaran terhadap lingkungan; (2) tidak menimbulkan kebisingan di lingkungan; (3) lebih bersih dan tidak menimbulkan polusi asap pada lingkungan sehingga cenderung lebih ramah lingkungan; (4) memiliki kinerja lebih cepat 1:2,5 kali dibandingkan teknologi sistem hammer; (5) tiang pancang lebih presisi dan mampu diaplikasikan pada tempat yang sempit dengan jarak $65 \mathrm{~cm}$ dari dinding bangunan eksisting; (7) pondasi tiang pancang yang terpasang lebih efektif, efisien dan bisa diandalkan kekuatan daya dukung pondasinya.

Cara kerja teknologi Hydraulic Static Pile Driver (HSPD): (1) menjepit di bagian tengah pile lalu ditekan secara hidrolis; (2) cukup praktis untuk memancang tiang hingga panjang 17 meter; (3) mampu membenamkan pile hingga 9 meter dibawah permukaan tanah, dengan bantuan doly yang bisa dicabut kembali secara mudah. 
Untuk pekerjaan pembuatan basement metode ini dapat lebih menghemat tiang pancang dan memudahkan pekerjaan pile cap, karena apabila menggunakan metode pemancangan lain, kemampuan pekerjaan ini hanya sekitar $1-2$ meter saja.

\section{Diskusi}

Saat ini masyarakat banyak menggunakan pondasi tiang pancang beton dengan baja tulangan serta tulangan spiral untuk pembangunan rumah tinggal atau proyek-proyek pembangunan gedung lainnya, karena pondasi tiang pancang beton memiliki beberapa kelebihan dibandingkan dengan pondasi tiang pancang kayu dan pondasi tiang pancang baja. Pondasi tiang pancang beton lebih panjang usianya, tidak mudah berkarat atau lapuk, memiliki kekuatan beton yang cukup tinggi dan sesuai kebutuhan, serta efisien dan ekonomis karena dibuat dengan cara prefabrikasi.

Untuk menghasilkan pemancangan pondasi tiang pancang beton yang cukup kokoh dan kuat serta presisi, maka kondisi tanah harus stabil dan baik. Kondisi tanah yang kurang baik akan mengganggu pemancangan pondasi. Contoh kasus adalah pada proyek pembangunan apartemen Mediterania Garden Residence 2 di Jakarta Barat. Kondisi tanah yang lembek di lokasi menyebabkan dorongan tanah ke samping cukup besar. Sehingga beberapa tiang pancang yang telah dipersiapkan menjadi miring dan perlu pemancangan ulang. Kondisi ini diatasi dengan dewatering yang cukup agar kondisi tanah menjadi stabil. Selain itu pekerjaan tanah juga dilakukan dengan membuat galian terasering yang cukup lebar dan timbunan tanah galian segera dikeluarkan dari lokasi tapak.

Kondisi tanah bekas rawa dan urukan juga dapat menimbulkan pergerakan horisontal ketika melakukan pemancangan tiang pancang beton. Namun hal ini tidak menjadi hambatan yang berarti apabila kedalaman tanah keras sudah dicapai pada kedalaman 17 meter. Kondisi demikian dapat dianggap cukup aman dan stabil. Tanah bekas rawa dan urukan dapat menimbulkan longsor pada saat pekerjaan galian tanah untuk basement, apabila kondisi curah hujan dan muka air tanah cukup tinggi. Dewatering yang cukup dapat mengatasi hal ini. Selain itu tanah yang bekas rawa dapat menimbulkan korosi baja tulangan pada tiang pancang beton. Karenanya keputusan untuk penggunaan pondasi tiang pancang beton juga harus memperhatikan kondisi tanah atau kondisi lapangan agar kerusakan beton dapat dihindari dan usia konstruksi lebih panjang. Panjang tiang dan jumlah tumpukan tiang pancang juga perlu diperhatikan karena dapat mempengaruhi daya dukung tiang pancang.

Tuntutan kenyamanan lingkungan, ketepatan dan kecepatan pekerjaan pemancangan menyebabkan para ahli berpikir keras untuk menjawab tantangan tersebut dan menemukan teknologi terbaru 'Press in Pile' atau teknologi Hydraulic Static Pile Driver (HSPD). Teknik ini mengurangi dampak yang dapat mengganggu lingkungan seperti getaran yang keras yang dapat menyebabkan kerusakan dan keretakan bangunan tetangga, polusi udara akibat asap dari proses pemancangan, dan kebisingan suara yang sangat mengganggu pendengaran masyarakat sekitar proyek yang sedang dibangun.

Aplikasi teknologi Hydraulic Static Pile Driver (HSPD) sudah dicoba pada proyek pembangunan perumahan di Pantai Indah Kapuk - Jakarta Utara (Gambar 4) dan proyek pembangunan Rusunami Cawang - Jakarta Timur (Gambar 5), yang dibangun di lingkungan padat hunian dan bangunan seperti perumahan, bangunan sekolah, masjid dan perkantoran, dan lain sebagainya. Teknologi ini ternyata mampu mengurangi dan meminimalkan ketidaknyamanan terhadap lingkungan saat pengerjaan pondasi tiang pancang. 


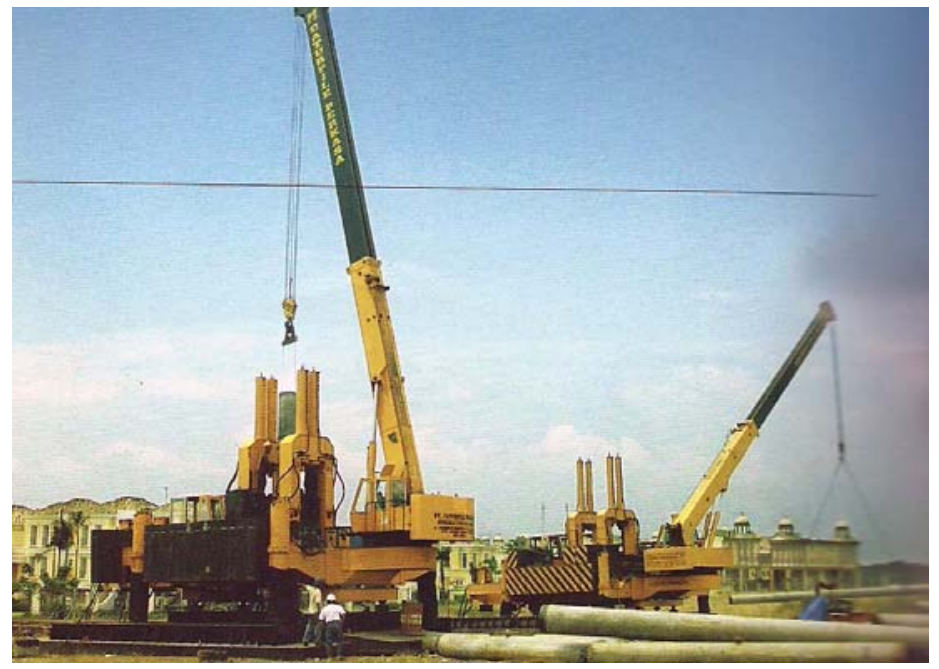

Gambar 4 Aplikasi teknologi Hydraulic Static Pile Driver (HSPD) pada proyek pembangunan perumahan di Pantai Indah Kapuk - Jakarta Utara (Tekno Konstruksi, 2008)

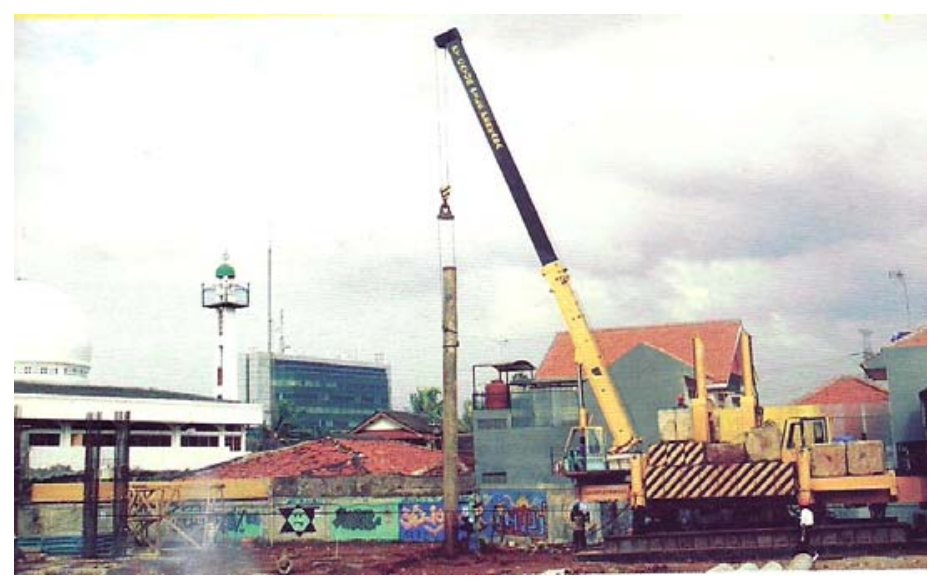

Gambar 5 Aplikasi teknologi Hydraulic Static Pile Driver (HSPD) pada proyek pembangunan Rusunami Cawang - Jakarta Timur (Tekno Konstruksi, 2008).

Contoh lain dari aplikasi Hydraulic Static Pile Driver (HSPD) adalah pada proyek apartemen Universitas Ciputra B (24 lantai) di Surabaya. Dari hasil penelitian analisis produktivitas pemancangan tiang pancang pada bangunan apartemen didapatkan hasil bahwa pemancangan yang baik dan benar akan menghasilkan nilai produktivitas yang diharapkan dan pada akhirnya akan mempengaruhi nilai apartemen secara keseluruhan termasuk nilai jualnya. Faktor-faktor yang mempengaruhi produktivitas antara lain sumber daya manusia, tiang pancang dan alat pancang. Proses pemancangan dengan sistem jack-in memakai alat Hydraulic Static Pile Driver (HSPD) pada bangunan tinggi tersebut menunjukkan produktivitas paling tinggi $(0.509 \mathrm{~m} / \mathrm{menit})$ dan paling rendah (0.406 $\mathrm{m} / \mathrm{menit})$. Nilai produktivitas tergantung pada panjang tiang pancang dan satuan waktu yang ditinjau dari durasi pemancangan (Limanto, 2009).

Hal lain yang perlu dipertimbangkan apabila menggunakan metode Hydraulic Static Pile Driver (HSPD) adalah mutu beton pile (tiang pancang) harus sangat diperhatikan agar tidak terjadi retak atau kerusakan fisik pada pile saat dilakukan penetrasi atau pemancangan tiang. 
Semakin tinggi ilmu pengetahuan dan teknologi yang berkembang sangat membantu dan memudahkan serta mempercepat proses pembangunan proyek-proyek gedung dan rumah tinggal. Hasil temuan material tiang pancang beton yang terbaru dan teknologi pemancangan tiang pancang terbaru dan canggih, dapat mengurangi dampak negatif pada lingkungan, bahkan mendukung efisiensi tenaga, efisiensi waktu dan biaya pelaksanaan kerja di lapangan.

\section{PENUTUP}

Pondasi tiang pancang adalah elemen bangunan yang berfungsi menyalurkan beban struktur bangunan ke tanah. Pondasi tiang pancang digunakan apabila kondisi tanah relatif stabil dan kedalaman tanah keras tidak terletak jauh di bawah permukaan tanah. Biasanya sebelum dilakukan pemancangan akan diadakan penyelidikan tanah untuk menentukan kedalaman tanah keras. Pondasi tiang pancang dapat terbuat dari kayu keras, beton dan baja (pipa atau profil). Penampang pondasi dapat berbentuk segitiga atau segiempat. Karena kelemahan dan keterbatasan jenis pondasi tiang pancang kayu dan tiang pancang baja, maka proyek-proyek pembangunan gedung lebih banyak menggunakan pondasi tiang pancang beton dengan baja tulangan serta tulangan spiral. Keuntungan menggunakan tiang pancang beton adalah pengerjaan pondasi menjadi efisien, mudah dan praktis. Penggunaan pondasi tiang pancang beton harus memperhatikan kondisi tanah atau kondisi lapangan, dan menghitung beban yang nanti akan dipikul oleh pondasi tiang pancang.

Saat ini cara pemancangan tiang pancang banyak menggunakan drop hammer atau sistem jacked piling sampai menyentuh tanah keras. Kendala yang ditemui di lapangan terkait pekerjaan pemancangan pondasi tiang pancang adalah kondisi tanah yang lembek, bekas rawa atau tanah urukan yang dapat mengganggu pemancangan pondasi.

Teknologi Hydraulic Static Pile Driver (HSPD) atau 'Press in Pile' adalah metode pemancangan terbaru sebagai solusi pemancangan pondasi tiang pancang pada lingkungan padat hunian. Teknik ini mengurangi bahkan dapat menghilangkan dampak yang mengganggu lingkungan (getaran, polusi udara dan polusi suara) saat pemancangan tiang pancang. Secara umum teknologi 'Press in Pile'mengurangi masalah lingkungan, lebih praktis, lebih cepat dan lebih ekonomis. Apabila pemancangannya tepat, baik dan benar akan menghasilkan nilai produktivitas bangunan yang menguntungkan dan sesuai harapan.

\section{DAFTAR PUSTAKA}

Fahirah F. (2007). Korosi pada beton bertulang dan pencegahannya. Jurnal SMARTek (Sipil-MesinArsitekur-Elektro), 5(3), ISSN 1693-0460.

Limanto, Sentosa (2009). Analisis produktivitas pemancangan tiang pancang pada bangunan tinggi apartemen. Prosiding Seminar Nasional 2009, Jurusan Teknik Sipil, FT-UKM, 15 Agustus 2009.

Nugroho, Soewignjo Agus, et.al. (2011). Studi pengaruh variasi panjang tiang terhadap daya dukung kelompok tiang (model tes skala lab). Jurnal Sains dan Teknologi, 10(2). 